\title{
ASSESSMENT OF BALANCE FUNCTIONS AND PRIMITIVE REFLEXES IN CHILDREN WITH LEARNING DISABILITY
}

\author{
Nagwa Hazzaa ${ }^{1}$, Amany Shalaby ${ }^{1}$, Sahar Hassanein ${ }^{2}$, Fathy Naeem ${ }^{1}$, \\ Ahmed Khattab ${ }^{3}$ and Nancy Metwally ${ }^{4}$
}

\author{
${ }^{1}$ Audiology Unit, ORL Department, \\ ${ }^{2}$ Pediatrics Department, \\ ${ }^{3}$ Phoniatrics Unit, ORL Department, \\ Faculty of Medicine, Ain Shams \\ University, Cairo, Egypt \\ ${ }^{4}$ Abou El-Monagga central \\ Hospital, Cairo, Egypt \\ Corresponding author \\ Nancy Metwally Aly Moustafa, \\ Mobile: (+20) 01001233460 \\ E.mail: \\ doc_Nancy_86@hotmail.com \\ Received: 25/11/2020 \\ Accepted: $17 / 12 / 2020$
}

Online ISSN: 2735-3540

\begin{abstract}
Background: Persistence of primary reflexes can indicate poor neurological development and immaturity within the nervous system. As dyslexia is a neurodevelopmental disorder that involves more than just reading difficulties so it's important to investigate primitive reflexes and balance functions in dyslexics.
\end{abstract}

Aim of the Work: To assess balance functions, primitive reflexes in dyslexics.

Subjects and Methods: The present study was conducted on 60 children divided into two subgroups. Control group consists of 20 normal children and study group consists of 40 children with dyslexia (diagnosed by Arabic Reading Screening test (ARST) and Modified Arabic Dyslexia Screening Test (MADST). Both study and control groups aged from 6 6/12 to 9 years old. They were subjected to clinical diagnostic tests for primitive reflexes and balance office tests (Romberg, unilateral stance, Fukuda stepping test, modified clinical test of sensory interaction in balance (mCTSIB).

Results: The study group demonstrated poor balance measured with unilateral stance compared to control group. Sixty percent of the study group has retained primitive reflexes.

Conclusions: Dyslexic children have poor balance compared to normal children and they have retained primitive reflexes supporting poor neurological development. Assessment of balance functions is recommended to be included within the test battery of dyslexics for better quality of life.

Key Words: Dyslexia, Balance, primitive reflexes.

\section{INTRODUCTION:}

Learning Disabilities (LDs) are neurobiological disorders in children characterized by an academic functioning that is below the level that would be expected given their age, IQ and grade level in school. It interferes significantly with academic performances or daily life activities that require reading, writing or calculation skills ${ }^{(1)}$. In Egypt $16.6 \%$ of primary school students are at risk for $\mathrm{LD}^{(2)}$. Dyslexia is the most common LD, accounting for at least $80 \%$ of all $\mathrm{LDs}^{(3)}$.
Dyslexia is characterized by problems with accurate or fluent word recognition and poor decoding despite adequate intelligence, motivation, and educational opportunities; these difficulties are believed to stem from a deficit in the phonological component of language $^{(4)}$.

In addition to impairment in phonological processing, some studies have noted other rather subtle deficits in motor and perceptual domains, such as manual finger tasks $^{(5)}$ and balance ${ }^{(6)}$. 
Primitive reflexes are automatic stereotyped movement patterns outside voluntary control which direct the movements of the fetus and infant during the first months of life ${ }^{(7)}$. At the age of three years the primitive reflexes should be fully integrated and no longer interfere with movements, and replacement reflexes, called postural reflexes, emerge ${ }^{(8)}$. Postural reflexes are more mature patterns of response that control balance, coordination and sensory motor development.

The persistence of primary reflexes can indicate poor neurological development and immaturity within the nervous system ${ }^{(\mathbf{9})}$. As dyslexia is a neurodevelopmental disorder that involves more than just reading difficulties so it's important to investigate primitive reflexes and balance functions in dyslexics.

\section{Subject and methods:}

Sixty children were included in this study divided into two subgroups, control group consists of 20 normal children and study group consists of 40 children with dyslexia; both study and control groups age ranged from $66 / 12$ to 9 years.

Study group children were selected from those attending phoniatric clinic Ain Shams University complaining from learning disability and diagnosed as dyslexics. The diagnosis of Dyslexia was according to Arabic Reading Screening test (ARST) $^{\mathbf{1 0})}$ and Modified Arabic Dyslexia Screening Test (MADST) ${ }^{(11)}$ where scores below the 25th percentile of age matched norms.

All children have normal hearing sensitivity and average IQ $(<90$ by Stanford Bient Intelligence Scale). Children with hearing loss, below average IQ, blindness, gross motor disability or behavioral abnormality (attention deficit, autism, etc) were excluded.

All subjects underwent the following: Full history taking, general examination, otological examination, balance office test (Romberg, unilateral stance, Fukuda stepping test \& mCTSIB), and clinical examination for presence of Primitive reflexes $^{(\mathbf{1 2})}$.

Primitive reflexes (PR): Testing is repeated for 2 trials ranged to 6 trials according to the tested reflex, the reflex is considered retained if it present even in only one trial ${ }^{\mathbf{1 2})}$. These are:

Asymmetrical tonic neck reflex (ATNR): The child was instructed to stand with feet together, arms held straight out a head at shoulder level with hand relaxed at the wrist. The examiner instruct the child to keep his/her arms in the same position while turning his/her head until the chin is parallel with shoulder, pause for 10 seconds, turns the head to the midline pause for 10 seconds then rotates the head to the other side. The procedure was done 4 times. Observation: any movement of the hand or arm on the side to which the head was turned means that reflex is retained.

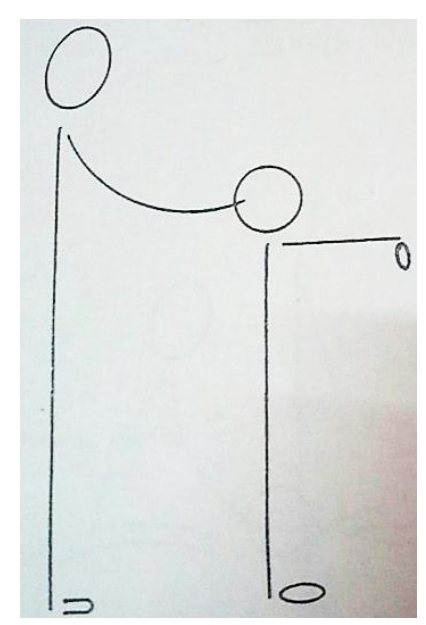

Fig. 1: A draw showing Asymmetrical tonic neck reflex testing

Tonic labyrinthine reflex (TLR): The child was instructed to stand with feet together, arms at the sides of the body. The child was instructed to slowly tilt his/her head back into the extended position, and then close eyes. Pause for 10 second then ask the child to slowly move his/her head forward as if looking at the toe, maintain for 
further 10 seconds. This was done for 6 times. Observation: any loss or alternation of balance as a result of head movements means presence of the tonic labyrinthine reflex.

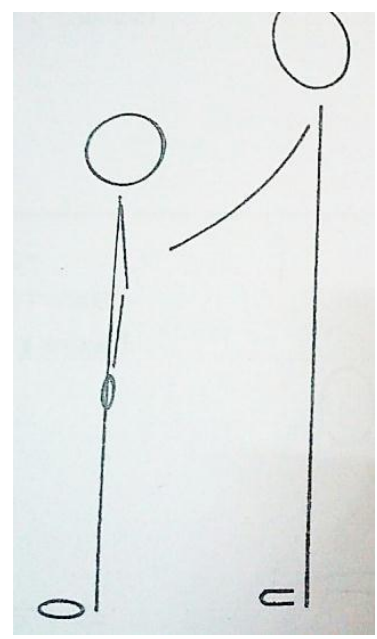

Fig. 2: A draw showing Tonic labyrinthine reflex testing

Grasp reflex: The child was instructed to stand with arms bent and palm upturned in a flexed relaxed position, elbows away from the body. The examiner gently stroke with pen along the creases of the palm, done twice. Observation: any movements of the fingers or thumb inwards towards the stimulus means presence of grasp reflex.

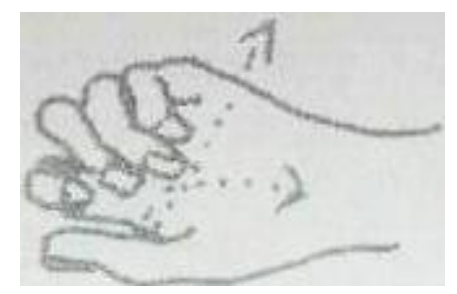

Fig. 3: A draw showing Grasp reflex testing

Symmetrical tonic neck reflex (STNR): The child was instructed to site in the four point kneeling position (table position) and to maintain in this position with slowly moving his/her head to look upward, hold 5 seconds and then slowly move his/her head downward, repeated up to 6 times. Observation: tremors in one or both arms or hip movements, bending of the arms as a result of flexion of the head or arching of the back means that this reflex is retained.

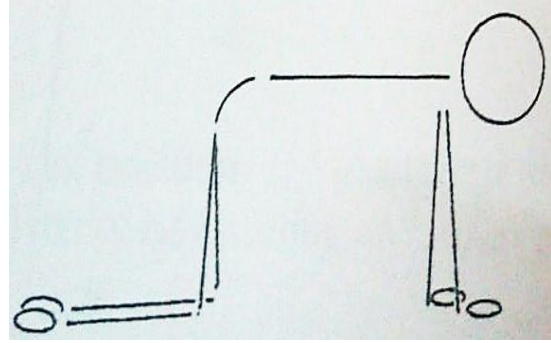

Fig. 4: A draw showing Symmetrical tonic neck reflex testing

Landau reflex: The child was instructed to lay on the prone position with arms at right angle to the shoulder. Then asked to lift upper trunk, arms and hands off the floor, keeping feet on the floor, maintain elevating for 5 second. This was repeated twice. Observation: involuntary lifting of the feet or lower legs as a result of rising torso. This means retained reflex.

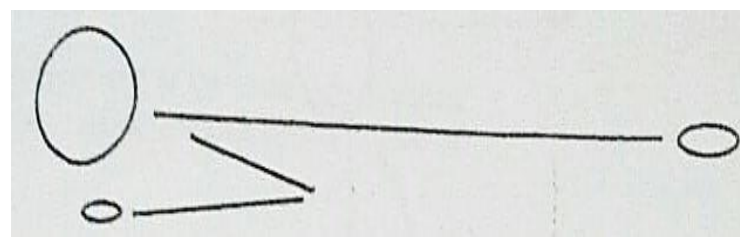

Fig. 5: A draw showing Landau reflex testing

Ethical Considerations: oral consent was obtained from all individuals and their parents before testing after explaining the aim of the study and procedure to be done.

Statistical Analysis: Independent Samples T test was used for comparison of parametric quantitative data between the two groups and Mann Whitney test for nonparametric quantitative data. For comparison of qualitative data between groups: Fisher's exact test was used. Reported results are considered significant for $\mathrm{p}<0.05$.

\section{RESULTS:}

\section{Personal \&Demographic Data:}

Both study and control group are age and gender matched. Most of the study\& control groups are Rt handed (Table 1\&2). 
Table 1: Age, Gender\& Handedness distribution in study and control groups:

\begin{tabular}{|c|c|c|c|c|}
\hline \multicolumn{2}{|c|}{} & $\begin{array}{c}\text { Study group } \\
(\mathrm{n}=40)\end{array}$ & $\begin{array}{c}\text { Control group } \\
(\mathrm{n}=20)\end{array}$ & P value \\
\hline \multirow{2}{*}{ Age } & Range & $(6.5-9)$ & $(6.5-9)$ & 0.07 \\
& Mean \pm SD & $7.9 \pm 0.4$ & $8.1 \pm 0.4$ & 0.5 \\
\hline Gender & Male & $26(65 \%)$ & $11(56.1 \%)$ & 1 \\
& Female & $14(35 \%)$ & $9(43.9 \%)$ & $19(95 \%)$ \\
\hline Handedness & RT & $37(92.5 \%)$ & $1(5 \%)$ & \\
& LT & $3(7.5 \%)$ & & \\
\hline
\end{tabular}

Table 2: Complaint distribution in the study group:

\begin{tabular}{|c|c|}
\hline Complaint & Study group \\
\hline Poor memory and attention & $14(35 \%)$ \\
Poor scholastic achievement & $13(32.5 \%)$ \\
Inconsistent response to soft sounds & $2(5 \%)$ \\
Poor reading and writing & $11(27.5 \%)$ \\
\hline
\end{tabular}

The main complaint of the study group is poor memory\& attention.

\section{Balance Office tests evaluation results:}

Study group showed significant instability during performing unilateral leg stance compared to the control group in both

Table 3: Comparison between study and control groups as regards unilateral leg stance performance timing in seconds:

\begin{tabular}{|c|c|c|c|c|c|}
\hline \multirow{2}{*}{ Unilateral stance } & \multicolumn{2}{|c|}{ Study group } & \multicolumn{2}{|c|}{ Control group } & \multirow{2}{*}{ P value } \\
\cline { 2 - 5 } & Median & *IQR & Median & *IQR & $<0.001^{*}$ \\
\hline Eye opened (sec.) & 13 & $(8-21)$ & 26.5 & $(21.5-29)$ & $<0.001^{*}$ \\
\hline Eye closed $(\mathrm{sec})$. & 5 & $(4-7.5)$ & 11 & $(10-13.5)$ & \\
\hline
\end{tabular}

*Inter quartile range

III. Percentage of retained primitive reflexes in the study groups:

Sixty seven percent of the study group has at least one retained primitive reflexes;

Table 4: Percentage of persistence of primitive reflexes in the study group:

\begin{tabular}{|c|c|c|}
\hline \multirow{2}{*}{ Primitive reflexes } & \multicolumn{2}{|c|}{ Study group } \\
\cline { 2 - 3 } & No & $\%$ \\
\hline Grasp reflex & 13 & $32.5 \%$ \\
\hline ATNR & 4 & $10 \%$ \\
\hline STNR & 14 & $35 \%$ \\
\hline TLR & 10 & $25 \%$ \\
\hline Landau reflex & 8 & $20 \%$ \\
\hline
\end{tabular}

STNR \& Grasp reflexes are the most prevalent retained reflexes in the study group.

\section{DISCUSSION:}

The purpose of this study was to assess balance function sand primitive reflexes in dyslexic children. on other hand control group didn't have any retained primitive reflexes. eye opened \& eye closed conditions (table $3)$. There was no significant difference in Romberg, Fukuda or mCTSIB tests. 
Banai \& Ahissar ${ }^{(13)}$; Alsulami ${ }^{(14)}$ have indicated lower memory skills among dyslexics.

Memory is vital to the acquisition of reading, as memory skills are important to remember letters, sounds represented by letters, letter blends, sight words, decoding strategies and word meanings ${ }^{(3)}$. A recent meta-analysis study by Peng et al. ${ }^{(15)}$ found that there is a significant relation between working memory and measures of reading decoding/fluency and reading comprehension in children.

\section{Balance office tests:}

There was significant postural instability in the study group compared to control subjects during balancing on one leg in both eye opened, eye closed conditions Table (3).

In accordance with the present study results, previous studies comparing postural stability in dyslexics and non- dyslexics on a normal surface during unperturbed single leg stance revealed a significant difference between groups with eye opened condition $(\mathbf{1 6 , 1 7 )}$ and with both eye opened and closed conditions $^{(\mathbf{1 8})}$.

Romberg test was normal in all dyslexics; this test could be easy for dyslexic children to perform. There was no significant difference between dyslexics and controls in mCTSIB test. Although many dyslexics could perform mCTSIB without moving their arms, legs or open their eyes in condition 4, they showed body sway specially during performing condition 4 that couldn't be objectively measured.

It is well known that postural control involves a complex relationship between sensory information and motor activity, meaning that children need to learn how to automatically adapt their body in order to achieve good postural control $^{(\mathbf{1 9})}$.

According to the cerebellar hypothesis of dyslexia Fawcett \& Nicolson ${ }^{(20)}$ the ability to learn how to perform tasks with automaticity could be deficient in dyslexic children, leading to poor ability in reading, writing, and the performance of other tasks such as postural control.

\section{Primitive reflexes evaluation:}

The study group has high percentage of retained primitive reflexes. According to data sixty percent of them have at least one retained primitive reflex. The STNR\& Grasp reflexes are the most prevalent retained reflexes in the study group (Table 4 ).

This is in agreement with Bilbilaj et al. ${ }^{(21)}$ they measured primitive retained reflexes in children with learning disability aged from 6 to 10 years old, they found that those children had a high percentage of retained primitive reflexes compared to normal children. ATNR, TLR and STNR were observed in all children studied, Grasp reflex was observed in $64.2 \%$ of them.

The present study suggests that persistence of primary reflexes and poor balance functions support poor neurological development and immaturity within the nervous system in dyslexics.

Conclusion: Dyslexic children have impaired postural stability compared to normal children and have retained primitive reflexes supporting poor neurological development in dyslexia. Assessment of balance functions is recommended to be included within the test battery of dyslexics for better quality of life.

\section{REFERENCES}

1. Margari L, Buttiglione M, Craig F, Cristella A, Giambattista C, Matera E, Operto F, Simone M (2013): Neuropsychopathological comorbidities in learning disorders. BMC Neurol; (13): 13- 198.

2. Ismail R, Mohamed H, Soltan B (2019): Prevalence of learning disabilities among a sample of primary school students. SSAMFG, 3(1):125-130. 
3. Sharma S, KohliA, Padhy S(2018): Specific Learning Disabilities: Issues that Remain Unanswered. Indian J PsycholMed.40(5): 399-405.

4. Lyon R, Shaywitz S, Shaywitz S.(2003): A Definition of Dyslexia. Annals of Dyslexia 53(1):1-14

5. Birkett $\mathrm{E}$ and Talcott $\mathbf{J}$ (2012): Interval timing in children: effects of auditory and visual pacing stimuli and relationships with reading and attention variables. PLoS ONE, 7:42- 820 .

6. Stoodley C and Schmahmann J (2009): Functional topography in the human cerebellum: a meta-analysis of neuroimaging studies. Neuroimage, 44: 489-501.

7. Castiello U, Becchio S, Zoia C, Nelini L, Sartori L and Blason (2010): Wired to be social: The ontogeny of human interaction. PLoS One, 5 (10): 13199.

8. Fong W, Tsang $\mathrm{W}$ and $\mathrm{Ng} \mathrm{G}$ (2012): Altered postural control strategies and sensory organization in children with developmental coordination disorder. Human Movement Science, 31 (5): 13171327.

9. Parfrey K, Gibbons S, Drinkwater E and Behm D (2014): Effect of head and limb orientation on trunk muscle activation during abdominal hollowing in chronic low back pain BMC Musculoskeletal Disorders, 15 (1).

10. EL Sady S, Bassiouny S, El Dorry G, Hegazi M, Gamal n and Khaled D (2014): Developing an Arabic Reading Screening Test for ages 5-9 years (ARST). Ain Shams medical journal,65(1-3),203-209

11. EL Fiky Y, EL Sady S and Hegazi M (2016): Modification and standardization of Egyptian dyslexia screening test for children. Ain Shams medical journal, 67(1,2,3),127-134
12. Goddard Blythe, S. (1996): A teacher's window Into the child's mind. Eugene: Fern Ridge Press.144.

13. Banai K, Ahissar M. (2010): On the importance of anchoring and the consequences of its impairment in dyslexia. Dyslexia; 16:240-257.

14. 14-Alsulami S (2019): The Role of Memory in Dyslexia. Australian International Academic Centre. 7(4): 2202-9478.

15. Peng P., Barnes M., Wang C., Wang W., Li S., Swanson H. L., Tao S: (2018). A metaanalysis on the relation between reading and working memory. Psychological Bulletin, 144, 48-76.

16. Moe-Nilssen R, Helbostad JL, Talcott JB, Toennessen FE (2003) Balance and gait in children with dyslexia. Exp Brain Res 150:237-244.

17. Stoodley, C.J.,Fawcett, A.J., Nicolson, R.I.,Stein, J.F. (2005) Impaired balancing ability in dyslexic children. Exp Brain Res, 167: 370-380.

18. Pozzo, T., Vernet, P., Creuzot-Garcher, C., Robichon, F., Bron, A., \&Quercia, P. (2006): Static postural control in children with developmental dyslexia. Neuroscience Letters, 403(3), 211-215

19. Barela, J. A., Jeka, J. J., \& Clark, J. E. (2003). Postural control in children: Coupling to dynamic somatosensory information. Experimental Brain Research, 150, 434-442.

20. Fawcett A, Nicolson R (2004) Dyslexia: the role of the cerebellum. Eletronic J Res Educ Psych 2: 35-58.

21. Bilbilaj S, Gjipali A, ShkurtiF(2017): Measuring Primitive Reflexes in Children with Learning Disorders. European Journal of Multidisciplinary Studies; 2, 5. 


\section{تقييم وظائف الإتزان وردود الفعل الأولية في الأطفال ذوي صعوبات التعلم}

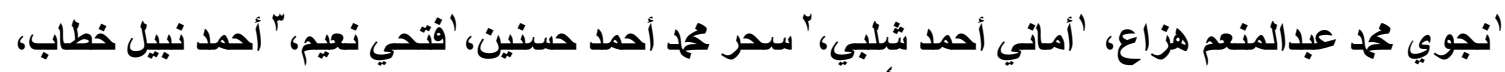

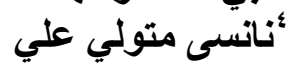

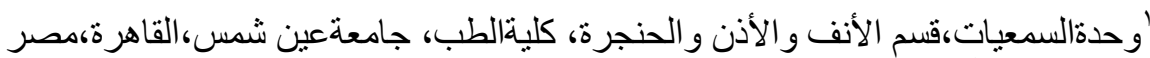

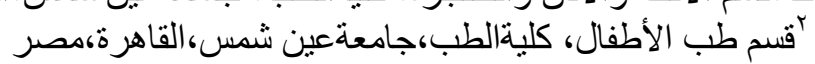

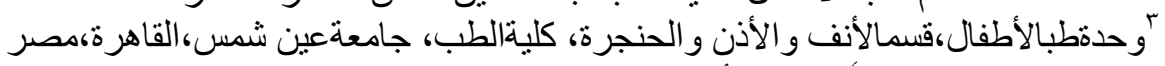

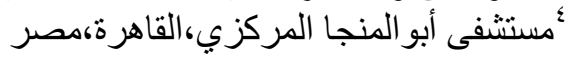

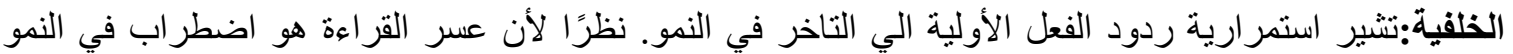

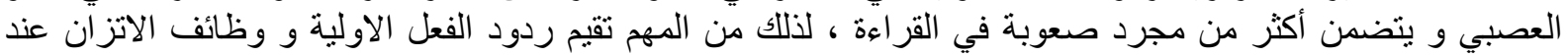
المصابين بعسر القر اءة.

الهلف من الاراسة: تقييم وظائف الإتزان وردود الفعل الأولية في الأطفال يعانون من عسر القر اءة..

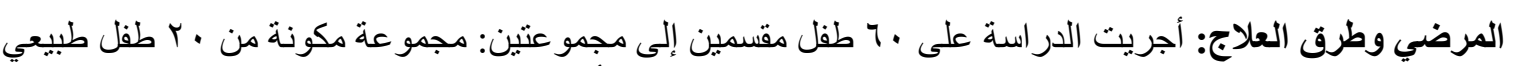

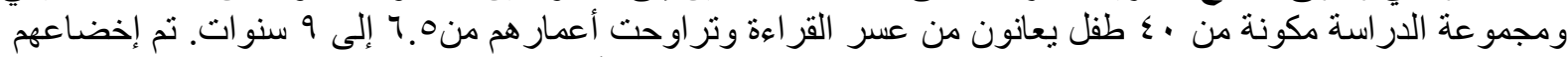

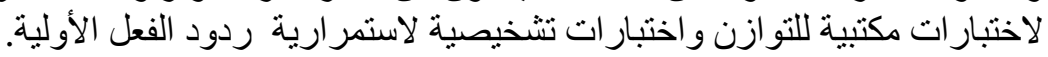

النتائج: كان لدى مجموعة الدراسة ضعف في النوازن مقارنة بالأطفال الطبيعية كما وجدت ردود الفعل الأولية في لإنه . $\%$ \% 1 .

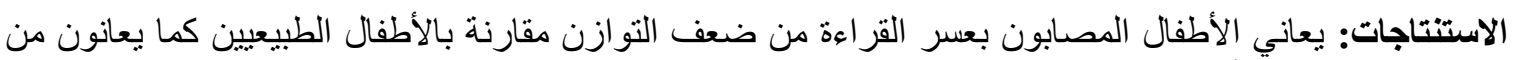

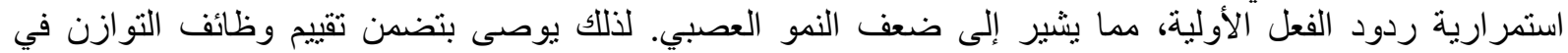
اختبارات عسر القر اعة و ذللك لحياة افضل. 